\title{
Hunger for Home Delivery: Cross-Sectional Analysis of the Nutritional Quality of Complete Menus on an Online Food Delivery Platform in Australia
}

\author{
Celina Wang ${ }^{1, *,+} \mathbb{D}$, Andriana Korai ${ }^{1, *,+}$, Si Si Jia ${ }^{2}$, Margaret Allman-Farinelli ${ }^{1} \mathbb{D}$, Virginia Chan ${ }^{1}$, \\ Rajshri Roy $^{3}\left(\mathbb{D}\right.$, Rebecca Raeside ${ }^{2}\left(\mathbb{D}\right.$, Philayrath Phongsavan ${ }^{4}$, Julie Redfern ${ }^{2,5} \mathbb{D}^{\text {, Alice A. Gibson }}{ }^{6} \mathbb{D}$ \\ and Stephanie R. Partridge 2,4 (D)
}

Citation: Wang, C.; Korai, A.; Jia, S.S.; Allman-Farinelli, M.; Chan, V.; Roy, R.; Raeside, R.; Phongsavan, P.; Redfern, J.; Gibson, A.A.; et al. Hunger for Home Delivery:

Cross-Sectional Analysis of the Nutritional Quality of Complete Menus on an Online Food Delivery Platform in Australia. Nutrients 2021, 13, 905. https://doi.org/10.3390/ nu13030905

Academic Editor: Antoni Pons

Received: 28 January 2021

Accepted: 6 March 2021

Published: 11 March 2021

Publisher's Note: MDPI stays neutral with regard to jurisdictional claims in published maps and institutional affiliations.

Copyright: (C) 2021 by the authors. Licensee MDPI, Basel, Switzerland. This article is an open access article distributed under the terms and conditions of the Creative Commons Attribution (CC BY) license (https:/ / creativecommons.org/licenses/by/ $4.0 /)$.
1 Nutrition and Dietetics Group, School of Life and Environmental Science, Charles Perkins Centre, The University of Sydney, Sydney, NSW 2006, Australia; margaret.allman-farinelli@sydney.edu.au (M.A.-F.); vcha3326@uni.sydney.edu.au (V.C.)

2 Westmead Applied Research Centre, Faculty of Medicine and Health, The University of Sydney, Sydney, NSW 2145, Australia; sisi.jia@sydney.edu.au (S.S.J.); rebecca.raeside@sydney.edu.au (R.R.); julie.redfern@sydney.edu.au (J.R.); stephanie.partridge@sydney.edu.au (S.R.P.)

3 Discipline of Nutrition and Dietetics, Faculty of Medical and Health Sciences, The University of Auckland, Auckland 1011, New Zealand; r.roy@auckland.ac.nz

4 Prevention Research Collaboration, Sydney School of Public Health, The University of Sydney, Sydney, NSW 2006, Australia; philayrath.phongsavan@sydney.edu.au

5 The George Institute for Global Health, The University of New South Wales, Camperdown, NSW 2006, Australia

6 Menzies Centre for Health Policy, Sydney School of Public Health, Faculty of Medicine and Health, The University of Sydney, Sydney, NSW 2006, Australia; alice.gibson@sydney.edu.au

* Correspondence: cwan7704@uni.sydney.edu.au (C.W.); akor4488@uni.sydney.edu.au (A.K.)

+ These authors contributed equally to this work.

Abstract: Online food delivery (OFD) platforms have changed how consumers purchase food prepared outside of home by capitalising on convenience and smartphone technology. Independent food outlets encompass a substantial proportion of partnering outlets, but their offerings' nutritional quality is understudied. Little is also known as to how OFD platforms influence consumer choice. This study evaluated the nutritional quality and marketing attributes of offerings from independent takeaway outlets available on Sydney's market-leading OFD platform (UberEats ${ }^{\circledR}$ ). Complete menus and marketing attributes from 202 popular outlets were collected using web scraping. All 13841 menu items were classified into 38 food and beverage categories based on the Australian Dietary Guidelines. Of complete menus, $80.5 \%(11,139 / 13,841)$ were discretionary and $42.3 \%(5849 / 13,841)$ were discretionary cereal-based mixed meals, the largest of the 38 categories. Discretionary menu items were more likely to be categorised as most popular (OR: 2.5, 95\% CI 1.9-3.2), accompanied by an image (OR: 1.3, 95\% CI 1.2-1.5) and offered as a value bundle (OR: 6.5, 95\% CI 4.8-8.9). Two of the three discretionary food categories were more expensive than their healthier Five Food Group counterparts $(p<0.02)$. The ubiquity of discretionary choices offered by independent takeaways and the marketing attributes employed by OFD platforms has implications for public health policy. Further research on the contribution of discretionary choices and marketing attributes to nutritional intakes is warranted.

Keywords: food environment; online food delivery; independent outlet; takeaway foods; fast food; nutrition; meal deals; adolescent; young adult

\section{Introduction}

The prevalence of consuming food prepared out of home, including takeaway stores, fast food chains, and restaurants, has increased globally due to busier lifestyles and demand for convenience $[1,2]$. Almost $50 \%$ of global respondents to a market research survey eat 
away from home at least once a week [3]. In Australia since the late 1980s, the proportion of total food expenditure on foods prepared outside of home has increased from $25 \%$ to $34 \%$ [4]. However, frequent consumption of takeaway food has been reported to be associated with poorer diet quality, namely, high levels of energy, total fat and sodium intake, and higher prevalence of obesity [2,5-7].

The physical, economic, political, and socio-cultural context in which consumers engage with the food system to make their decisions about acquiring, preparing, and consuming food is known as the food environment [8]. The existing food environment is being disrupted by the emergence of online food delivery (OFD) platforms, which have recorded a doubling in usage from 2018 to 2020 [9]. OFD platforms have been defined as "websites or smartphone applications set up for customers to select from food outlets' menu items to order food prepared away from the home for pick up or delivery by freelance couriers" [10]. Almost $30 \%$ of younger generations (15-to-34 years) use these OFD platforms and have recently been identified as their main users [11]. Food prepared outside of home has recently been reported to be most consumed by young people compared to other age groups [12]. Young people have also been reported to spend just under \$AUD 2000 per year on these foods [4].

Concerns have been raised about the nutritional quality of meals offered by OFD platforms. A recent cross-sectional observational study conducted by Partridge et al. in Sydney and Auckland, characterised 680 popular food outlets and their five to ten most popular menu items from UberEats ${ }^{\circledR}$, the market-leading OFD platform in Australia [10]. They found $86 \%$ of popular menu items were discretionary foods and beverages (also known as junk food), which are defined as items high in added salt, saturated fat, sugar and low in fibre by the Australian Dietary Guidelines $[10,13]$. Previous studies have described the nutritional composition of meals from takeaway franchises (chain stores that prepare and sell meals/snacks ready for immediate consumption, offered in specialised packaging, e.g., McDonalds ${ }^{\circledR}$, or $\mathrm{KFC}^{\circledR}$ ) that are subject to menu labelling [14,15]. However, independent takeaways (takeaway outlets that are not franchises, e.g., local kebab shop) [16], are not subject to this regulation and were reported to be the second largest (30\%) food outlet type on OFD platforms after takeaway franchises [10]. Only a few studies have explored the nutritional quality of food items provided by independent outlets $[5,10,17]$, highlighting a research gap exists for this food outlet classification. The collation of independent restaurants on a single platform provides a unique opportunity for efficient evaluation of the nutritional quality of menus from multiple independent takeaways.

OFD platforms have also revolutionised the way we purchase food prepared out of home by capitalising on smartphone technology and subsequently expanding our food choices beyond local food outlets $[18,19]$. The platforms allow users to order food, view enticing food images, and access other customers' reviews with an unprecedented ease [19]. A recent Australian study reported price, value for money food items, and appealing food images to heavily influence young people's preference to eat food prepared outside of home [20].

Marketing tactics that position foods to be first viewed and default popular choices may encourage their selection. Within an online grocery store context, options placed on the "first-screen" appear to be more commonly selected [21]. Such strategies are akin to the positioning of food items on supermarket shelves at eye-level and at check-out counters [22]. The position of an item within a physical menu and the use of popularity cues such as "Most Popular" have also been reported to sway consumer choice $[23,24]$. Popularity cues serve as an indicator of product demand and/or interest by other consumers [24].

Nutritional labelling at point-of-sale may also serve as a form of marketing to encourage choice, or in this case to guide consumers to healthier choices [25-27]. A study conducted at a New Zealand university also reported use of symbols on menus to label healthy foods influenced food selection [28].

The use of marketing techniques within the unique digital food environment of OFD platforms and the association with nutritional quality of menus offered warrants further investigation. 
Thus, this study's primary aim was to evaluate the nutritional quality of complete menus from popular independent takeaways available on a market-leading OFD platform in areas with high proportions of young consumers (15-34-years) in Australia. The secondary aim was to investigate the associations between the nutritional quality and marketing attributes of these menus, including a popularity cue, image use, prices, offerings as value bundles, nutritional information, and dietary labelling.

\section{Materials and Methods}

\subsection{Identification of Popular Independent Takeaways}

This study formed a new database of complete menus for food outlets that were identified by a previous cross-sectional study conducted in Sydney between 9 and 22 February 2020. The identification process is described in detail elsewhere [10]. The 10 most popular food outlets were extracted from the UberEats' "popular near you" section for areas with above-average populations of young people ( $>30 \% 15-34$ years), the leading users of OFD platforms [10]. Researchers were not logged into personal UberEats accounts to avoid biased results. This project focused on evaluation of the 202 independent takeaways identified from the previous study using the Food Environment Score Tool $[16,29,30]$. Independent takeaways have been defined as outlets that are not franchises, which prepare and sell meals or snacks, ready for immediate consumption, e.g., local kebab shop [16].

\subsection{Data Extraction}

Publicly available complete menus were extracted from the OFD website on September 10th 2020 (via web scraping, ScrapingSolutions). Complete menus include all menu items available from independent takeaways as displayed on their UberEats webpage. Data collected from these menus included the menu items' names, descriptions, UberEats categories, prices, images, nutritional information (e.g., the macronutrient profile), and any dietary labelling (e.g., vegan, vegetarian, or gluten-free). Table 1 provides a summary of definitions and derivations of the data extracted.

\subsection{Outcome Measures}

The primary outcome of this study was the nutritional quality of complete menus from popular independent takeaways. Secondary outcomes were the prevalence of marketing attributes for complete menus and their association with nutritional quality.

\subsubsection{Nutritional Quality}

All menu items from independent takeaways were classified into 38 food and beverage categories using a modified version of a classification system previously proposed for a sub-study of the existing MYMeals project (Supplementary Material, Tables S1 and S2) [7]. These food and beverage categories define menu items using food types derived from the Australian Dietary Guidelines' Five Food Group (FFG) and discretionary classifications [13]. FFG dishes (also known as core) contain food(s) or a combination of foods from the five food groups: vegetables and legumes/beans; fruit, grain (cereal) foods, mostly wholegrain, and/or high cereal fibre varieties; lean meats and poultry, fish, eggs, tofu, nuts and seeds, and legumes/beans; and milk, yoghurt, cheese and/or alternatives, and mostly reduced fat) $[10,13]$. Discretionary dishes are defined as items high in added salt, saturated fat, sugar, and low in fibre by the Australian Dietary Guidelines [10,13]. Some menu items lacked substantial data and were classified as "undetermined" as there were multiple categories to which assignment was possible (e.g., "drink" with no image or description provided). Other menu items were not edible (e.g., cutlery, or napkins) and classified as "non-consumable". Both the undetermined and non-consumable categories were excluded from data analysis. Where a menu item was not considered in the original classification system, the Australian Bureau of Statistics' (ABS) principles and list for identifying discretionary foods were used to assist categorisation [31]. A conservative approach in favour of FFG was taken when insufficient information was available to classify menu items as discretionary. For example, 
stir-fries without adequate detail in the description were classified as a FFG type dish although some stir-fries have excessive sodium. The database was sorted alphabetically by the UberEats food category and then by menu item name. Two dietetic researchers each classified half the database (AK, CW). A random $20 \%$ sample of the data was crosschecked by Accredited Practising Dietitians (SRP, SJ) with an agreement of $99.0 \%$ in the cross-checked sample.

Table 1. Summary of definitions and derivations of data extracted from complete menus of each independent takeaway and study outcomes.

\begin{tabular}{|c|c|}
\hline Data Extracted & Definition \\
\hline Menu item name & The name of menu items from a food outlet's webpage \\
\hline Menu item description & $\begin{array}{l}\text { The description provided for menu items from a food outlet's webpage. This description is located } \\
\text { below the menu item name. Not all menu items have descriptions. }\end{array}$ \\
\hline UberEats category & $\begin{array}{l}\text { The menu category, which menu items are grouped within on a food outlet's webpage } \\
\text { (e.g., Beverages, Main Meals). }\end{array}$ \\
\hline Catering and party packs & $\begin{array}{l}\text { Any menu items with "catering", "party", or similar terms in either the UberEats category or the menu } \\
\text { item name. These menu items were suspected to serve more than } 10 \text { people. }\end{array}$ \\
\hline $\begin{array}{l}\text { UberEats category } \\
\text { duplicate }\end{array}$ & $\begin{array}{l}\text { The duplicate menu items that varied only by the Uber- Eats category. These menu items were listed } \\
\text { both as "Most Popular" and as another UberEats category (e.g., Chicken Burger listed under Most } \\
\text { Popular and Burger categories). }\end{array}$ \\
\hline Meal deal & $\begin{array}{l}\text { Any menu item that included multiple food components which could be purchased individually from } \\
\text { the food outlet (e.g., burger with chips and drink). These menu items were available at a reduced price } \\
\text { compared to buying the individual components separately. This was determined using the menu item } \\
\text { description in the context of the food outlet's complete menu. }\end{array}$ \\
\hline Family deal & $\begin{array}{l}\text { Any menu item intended to serve more than one person and suspected to serve less than ten people. } \\
\text { These items contained the terms "for two", "for three", "family", or similar in the UberEATS category, } \\
\text { menu name or description. }\end{array}$ \\
\hline Study Outcomes & Definition \\
\hline $\begin{array}{l}\text { Discretionary food } \\
\text { or beverage }\end{array}$ & $\begin{array}{l}\text { Foods and beverages, which are defined as items high in added salt, saturated fat, sugar, and low in } \\
\text { fibre by the Australian Dietary Guidelines [10,13]. Internationally they are also referred to as junk food } \\
\text { or non-core. }\end{array}$ \\
\hline $\begin{array}{l}\text { Five Food Group (FFG) } \\
\text { food or beverage }\end{array}$ & $\begin{array}{l}\text { Foods and beverages, which have food(s)the or combination of foods from the five food groups defined } \\
\text { by the Australian Dietary Guidelines: vegetables and legumes/beans, fruit, grain (cereal) foods, mostly } \\
\text { wholegrain and/or high cereal fibre varieties; lean meats and poultry, fish, eggs, tofu, nuts and seeds } \\
\text { and legumes/beans; and milk, yoghurt cheese, and/or alternatives, mostly reduced fat }[10,13] \\
\text { Internationally these are also referred to as core foods. }\end{array}$ \\
\hline $\begin{array}{l}\text { Most popular } \\
\text { menu items }\end{array}$ & $\begin{array}{l}\text { Menu items listed as "Most Popular" in the UberEats category. These items are typically positioned at } \\
\text { the top of a food outlet's UberEats webpage and app interface, attracting greater visibility. } \\
\text { All other menu items are referred to as regular menu items. }\end{array}$ \\
\hline Value bundles & This is a collective term for meal deals, family deals and catering and party packs. \\
\hline Image & $\begin{array}{l}\text { The image accompanying the menu item name, description, and price. } \\
\text { Not all menu items have images. }\end{array}$ \\
\hline Price $(\$)$ & The price of menu items from a food outlet's webpage. \\
\hline Nutritional information & $\begin{array}{l}\text { Any information provided on the OFD platform that quantifies any macronutrient(s) of a menu item } \\
\text { (e.g., energy, protein) or micronutrient(s) (e.g., sodium). } \\
\text { Not all menu items have nutritional information. }\end{array}$ \\
\hline Dietary labelling & $\begin{array}{l}\text { Any menu item label associated with a dietary requirement (e.g., vegan). } \\
\text { Religious dietary labelling (e.g., halal) and heat scale labelling (e.g., spicy) was excluded from this data. } \\
\text { Not all menu items have dietary labelling. }\end{array}$ \\
\hline
\end{tabular}




\subsubsection{Marketing Attributes}

Marketing attributes included: popularity cue (category of "Most Popular"), price, value bundles, use of image, nutritional information, and dietary labelling. The data required to assess all marketing attributes, excluding value bundles, was extracted by the web scraping company. Value bundles such as catering and party packs, meal deals, and family deals were manually coded using the menu item name and description. The higher cost of value bundles was anticipated to inflate the median price and thus excluded from price analysis. Table 1 provides a summary of the definitions of these study outcomes.

\subsection{Data Analysis}

All data was collated on Microsoft Excel (Version 16.41, Microsoft Corporation, Redmond, Washington, DC, USA). Any food and beverage categories which were less than $10 \%$ of all menu items were grouped into four categories: Other Food (discretionary), Other Food (FFG), Other Beverage (discretionary), and Other Beverage (FFG). Descriptive statistics were used to evaluate the nutritional quality and marketing attributes of all menu items. Categorical variables (nutritional quality, popularity, value bundles, image, nutritional information and dietary labelling) were summarised using frequencies and proportions. Chi-squared tests with the Bonferroni multiple comparisons correction and odds ratios were used for categorical variables to identify significant differences between (i) discretionary and FFG menu items and (ii) most popular and regular menu items. The distribution of continuous variables (price) was assessed using histograms and measures of skewness and kurtosis. Continuous variables were summarised as medians and interquartile intervals. Kruskal-Wallis tests with multiple comparisons corrections were used for continuous variables to identify significant differences between (i) most popular and regular menu items and (ii) comparable discretionary and FFG food and beverage categories. All analyses were undertaken using SPSS Statistics Version 26 (IBM, Armonk, New York, NY, USA).

\section{Results}

\subsection{Selection of Menu Items}

A total of 14,103 menu items were available from complete menus of 196 independent takeaways (Figure 1). Menus from six of the independent takeaways were absent from the data extraction. After 262 undetermined, non-consumable and UberEATS category duplicate menu items were excluded, 13,841 menu items remained for analyses of nutritional quality and all marketing attributes, excluding price. Following further exclusion of 1107 value bundles ( 35 catering or party packs, 395 family deals, and 677 meal deals) 12,734 entries were available for price analysis.

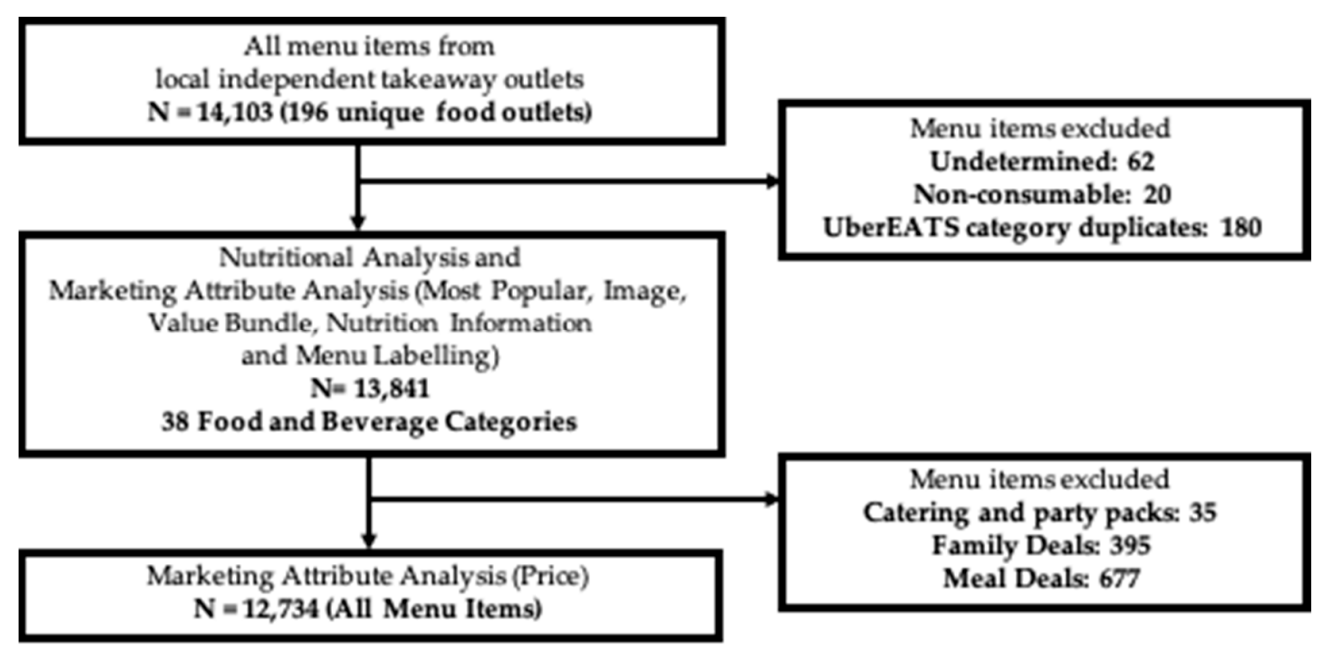

Figure 1. Flow diagram outlining inclusion of menu items in each analysis. 


\subsection{Nutritional Quality and Marketing Attributes}

\subsubsection{Nutritional Quality and Most Popular Menu Items}

The proportions of each food and beverage category for complete menus is depicted in Table 2 . The majority of menu items were discretionary $(80.5 \%, 11,139 / 13,841)$. The discretionary cereal-based mixed meal category was the largest category within complete menus $(42.3 \%, 5849 / 13,841)$ (Table 2). This category included pizzas, burgers, pides, pasta, wraps, sandwiches, and rolls. The second largest category was discretionary meat or alternativebased mixed meals $(13.9 \%, 1924 / 13,841)$. This group included items such as Halal snack packs (halal-certified doner kebab meat (e.g., lamb, chicken, or beef) and chips), charcoal chicken, deep-fried chicken, deep-fried seafood meals (e.g., fish and chips), and ribs.

Table 2. The proportion of food and beverage categories in complete menus $(N=13,841)$ from 196 independent takeaways. Categories are sorted in descending order.

\begin{tabular}{|c|c|c|c|}
\hline Type of Category & Food Categories & $n$ & $\%$ \\
\hline \multirow{11}{*}{ 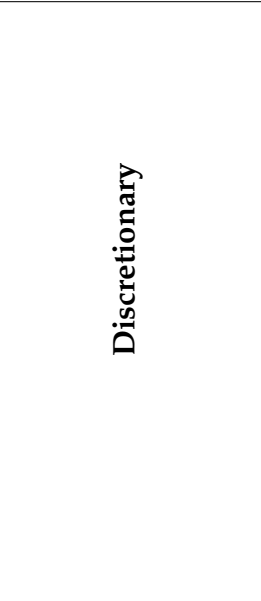 } & Cereal-Based Mixed Meal & 5849 & 42.3 \\
\hline & Meat Or Alternative Based Mixed Meal & 1924 & 13.9 \\
\hline & Sugar Sweetened Beverages & 776 & 5.6 \\
\hline & Savoury Sauces, Condiments And Spreads & 587 & 4.2 \\
\hline & Fried Potato (Or Similar) & 419 & 3.0 \\
\hline & Baked Goods/Desserts (Homemade Or Similar) & 402 & 2.9 \\
\hline & Vegetable-Mased Mixed Meal & 347 & 2.5 \\
\hline & Other Beverage $b$ & 318 & 2.3 \\
\hline & Iced Confectionary And Dairy-Based Desserts & 197 & 1.4 \\
\hline & Discretionary Milk Based Beverages & 194 & 1.4 \\
\hline & Other Food $^{a}$ & 126 & 0.9 \\
\hline \multirow{8}{*}{ U } & Cereal-Based Mixed Meal & 785 & 5.7 \\
\hline & Vegetable-Based Mixed Meal & 583 & 4.2 \\
\hline & Meat Or Alternative Based Mixed Meal & 475 & 3.4 \\
\hline & Water & 248 & 1.8 \\
\hline & Other Food ${ }^{\mathrm{c}}$ & 238 & 1.7 \\
\hline & Other Beverage ${ }^{d}$ & 211 & 1.5 \\
\hline & Juice & 162 & 1.2 \\
\hline & Total & 13,841 & \\
\hline
\end{tabular}

a Confectionery, Discretionary Snack Food (Savoury)—Packaged, Discretionary Snack Food (Sweet)—Packaged, Other Snack Food (Other), Processed Meats, b Alcohol, Energy Drinks, Non-Sugar Sweetened Beverages, Rehydration Beverages (Electrolytes), Water Based Flavoured Beverage-Sugar Not Determined, ' ${ }^{\mathrm{C}}$ Breads And Cereals, Dairy And Alternatives, Fats/Oils, Fruit, Legumes, Meat And Alternatives, Soup, Vegetables, Vegetables (Other), d Body Building And Performance Beverages, Coffee, Milk/Milk Alternatives, Milk/Milk Alternative Based Beverages, Tea.

Table 3 depicts the proportion of discretionary and FFG menu items within complete menus and each marketing attribute subgroup. Most popular menu items comprised $4.5 \%$ $(625 / 13,841)$ of complete menus and the majority of the most popular menu items were discretionary $(90.8 \%, 568 / 625)$ (Table 3). A discretionary item was more likely (OR: 2.5, 95\% CI 1.9-3.2) to be most popular compared to a FFG menu item. The discretionary cereal-based mixed meal category was the largest category from the most popular menu items $(57.0 \%, 357 / 625)$ (Supplementary Material, Table S3). The second-largest category for most popular menu items was discretionary meat or alternative-based mixed meals $(25.2 \%, 157 / 625)$ (Supplementary Table S3). 
Table 3. The proportion of discretionary menu items compared against FFG menu items within marketing attribute subgroups and complete menus ${ }^{1}$.

\begin{tabular}{ccccc}
\hline $\begin{array}{c}\text { Marketing } \\
\text { Attribute }\end{array}$ & $\begin{array}{c}\text { Discretionary } \\
\mathbf{( \% )}\end{array}$ & FFG (\%) & Total & $\begin{array}{c}\text { Odds Ratio } \\
\mathbf{( 9 5 \% ~ C I ) ~}\end{array}$ \\
\hline Most Popular & $568(90.8)$ & $57(9.2)$ & 625 & $2.5(1.9-3.2)$ \\
\hline Image & $2419(59.0)$ & $687(41.0)$ & 4097 & $1.3(1.2-1.5)$ \\
\hline Value Bundle & $1064(96.1)$ & $43(3.9)$ & 1107 & $6.5(4.8-8.9)$ \\
\hline Complete Menus & $11,139(80.5 \%)$ & $2702(19.5 \%)$ & 13,841 & \\
\hline
\end{tabular}

${ }_{1}^{1}$ The odds ratio was calculated for discretionary categories compared against FFG categories. Percentages are within each marketing attribute.

\subsubsection{Value Bundles}

The frequency of images and meal deals associated with (i) complete menus $(N=13,841)$ and (ii) the most popular menu items $(n=625)$ is depicted in Table 4 . Within complete menus, $8.0 \%(1107 / 13,841)$ were a value bundle. A higher proportion of discretionary menu items $(9.6 \%, 1064 / 11,139)$ were offered as a value bundle compared to FFG menu items $(1.6 \%, 43 / 2702)(p<0.001)$ (Table 4$)$. Discretionary menu items were 6.5 times more likely to be offered as a value bundle than FFG menu items (Table 3). Discretionary cereal-based mixed meals made up 66\% (729/1107) of all value bundles (Table 4). There was no significant difference in the number of value bundles within the most popular menu items compared to regular menu items $(p=0.549)$.

Table 4. Prevalence of images and value bundles for complete menus $(N=13,841)$ and most popular menu items $(n=625)$ of 196 independent takeaways ${ }^{1}$.

\begin{tabular}{|c|c|c|c|c|c|c|}
\hline \multirow{2}{*}{$\begin{array}{l}\text { Food \& Beverage } \\
\text { Group }\end{array}$} & \multirow{2}{*}{ Food \& Beverage Category } & \multirow{2}{*}{$\begin{array}{l}\text { Marketing } \\
\text { Attributes }\end{array}$} & \multicolumn{2}{|c|}{ Complete Menus } & \multicolumn{2}{|c|}{ Most Popular Menu Items } \\
\hline & & & $n$ & $\%$ & $n$ & $\%$ \\
\hline \multirow{16}{*}{$\begin{array}{c}\text { Food } \\
\text { (discretionary) }\end{array}$} & \multirow{2}{*}{ Cereal-Based Mixed Meal } & Image & 1846 & 31.6 & 318 & $89.1 *$ \\
\hline & & Value Bundle & 729 & 12.5 & 28 & $7.8^{*}$ \\
\hline & \multirow{2}{*}{ Meat Or Alternative-Based Mixed Meal } & Image & 680 & 35.3 & 137 & $87.3 *$ \\
\hline & & Value Bundle & 304 & 15.8 & 24 & 15.3 \\
\hline & \multirow{2}{*}{ Savoury Sauces, Condiments And Spreads } & Image & 87 & 14.8 & 0 & 0 \\
\hline & & Value Bundle & 2 & 0.3 & 0 & 0 \\
\hline & \multirow{2}{*}{ Fried Potato (Or Similar) } & Image & 146 & 34.8 & 14 & $87.5^{*}$ \\
\hline & & Value Bundle & 14 & 3.3 & 0 & 0 \\
\hline & \multirow{2}{*}{ Baked Goods/Desserts (Homemade Or Similar) } & Image & 149 & 37.1 & 8 & 100 \\
\hline & & Value Bundle & 2 & 0.5 & 0 & 0 \\
\hline & \multirow{2}{*}{ Iced Confectionary And Dairy-Based Desserts } & Image & 69 & 35.0 & 3 & 100 \\
\hline & & Value Bundle & 0 & 0 & 0 & 0 \\
\hline & \multirow{2}{*}{ Vegetable-Based Mixed Meal } & Image & 133 & 38.3 & 18 & $90.0 *$ \\
\hline & & Value Bundle & 12 & 3.5 & 1 & 5.0 \\
\hline & \multirow{2}{*}{ Other Food ${ }^{a}$} & Image & 35 & 27.8 & 2 & 66.7 \\
\hline & & Value Bundle & 1 & 0.8 & 0 & 0 \\
\hline \multirow{6}{*}{$\begin{array}{c}\text { Beverage } \\
\text { (discretionary) }\end{array}$} & \multirow{2}{*}{ Sugar Sweetened Beverages } & Image & 177 & 22.8 & 0 & 0 \\
\hline & & Value Bundle & 0 & 0 & 0 & 0 \\
\hline & \multirow{2}{*}{ Other Beverage ${ }^{b}$} & Image & 60 & 18.9 & 0 & 0 \\
\hline & & Value Bundle & 0 & 0 & 0 & 0 \\
\hline & \multirow{2}{*}{ Milk Based Beverages } & Image & 38 & 19.6 & 1 & 50.0 \\
\hline & & Value Bundle & 0 & 0 & 0 & 0 \\
\hline
\end{tabular}


Table 4. Cont.

\begin{tabular}{|c|c|c|c|c|c|c|}
\hline \multirow{2}{*}{$\begin{array}{c}\text { Food \& Beverage } \\
\text { Group }\end{array}$} & \multirow{2}{*}{ Food \& Beverage Category } & \multirow{2}{*}{$\begin{array}{l}\text { Marketing } \\
\text { Attributes }\end{array}$} & \multicolumn{2}{|c|}{ Complete Menus } & \multicolumn{2}{|c|}{ Most Popular Menu Items } \\
\hline & & & $n$ & $\%$ & $n$ & $\%$ \\
\hline \multirow{2}{*}{ Total Discretionary } & & Image & 3420 & $30.7^{* *}$ & 501 & $88.2 *$ \\
\hline & & Value Bundle & 1064 & $9.6^{* *}$ & 53 & 9.3 \\
\hline \multirow{8}{*}{ Food (FFG) } & \multirow{2}{*}{ Cereal-Based Mixed Meal } & Image & 166 & 21.1 & 20 & $90.9 *$ \\
\hline & & Value Bundle & 18 & 2.3 & 0 & 0 \\
\hline & \multirow{2}{*}{ Vegetable-Based Mixed Meal } & Image & 226 & 38.8 & 14 & $93.3^{*}$ \\
\hline & & Value Bundle & 9 & 1.5 & 0 & 0 \\
\hline & \multirow{2}{*}{ Meat Or Alternative-Based Mixed Meal } & Image & 129 & 27.2 & 15 & $78.9 *$ \\
\hline & & Value Bundle & 14 & 2.9 & 0 & 0 \\
\hline & \multirow{2}{*}{ Other Food ${ }^{c}$} & Image & 41 & 17.2 & 1 & 100 \\
\hline & & Value Bundle & 2 & 0.8 & 0 & 0 \\
\hline \multirow{6}{*}{ Beverage (FFG) } & \multirow{2}{*}{ Water } & Image & 69 & 27.8 & 0 & 0 \\
\hline & & Value Bundle & 0 & 0 & 0 & 0 \\
\hline & \multirow{2}{*}{ Other Beverage $^{\mathrm{d}}$} & Image & 20 & 9.5 & 0 & 0 \\
\hline & & Value Bundle & 0 & 0 & 0 & 0 \\
\hline & \multirow{2}{*}{ Juice } & Image & 26 & 16.0 & 0 & 0 \\
\hline & & Value Bundle & 0 & 0 & 0 & 0 \\
\hline \multirow{2}{*}{ Total FFG } & & Image & 677 & 25.1 & 50 & $87.7^{*}$ \\
\hline & & Value Bundle & 43 & 1.6 & 0 & 0 \\
\hline \multirow{2}{*}{ Total } & & Image & 4097 & 29.6 & 551 & $88.2 *$ \\
\hline & & Value Bundle & 1107 & 8.0 & 53 & 8.5 \\
\hline
\end{tabular}

${ }^{a}$ Confectionery, Discretionary Snack Food (Savoury)—Packaged, Discretionary Snack Food (Sweet)—Packaged, Other Snack Food (Other), Processed Meats. ${ }^{\mathrm{b}}$ Alcohol, Energy Drinks, Non-Sugar Sweetened Beverages, Rehydration Beverages (Electrolytes), Water Based Flavoured Beverage-Sugar Not Determined. ' Breads And Cereals, Dairy And Alternatives, Fats/Oils, Fruit, Legumes, Meat And Alternatives, Soup, Vegetables, Vegetables (Other). ${ }^{\mathrm{d}}$ Body Building And Performance Beverages, Coffee, Milk/Milk Alternatives, Milk/Milk Alternative Based Beverages, Tea. ${ }^{1}$ Percentages are within each Food \& Beverage Category where displayed, otherwise within the Total. ${ }^{*} p<0.01$ compared to regular menu items. ${ }^{* *} p<0.001$ compared to Total FFG (Complete Menus).

\subsubsection{Images}

Within complete menus $29.6 \%(4097 / 13,841)$ were accompanied by an image. A higher proportion of discretionary menu items $(30.7 \%, 3420 / 11,139)$ had images compared to FFG menu items $(25.1 \%, 677 / 2702)(p<0.001)$ (Table 4). Discretionary menu items were 1.3 times more likely to have an image than FFG menu items (Table 3). Most popular menu items were also more likely to have an image compared to the regular menu items $(p<0.01)$.

\subsubsection{Price}

Table 5 depicts the prices of the (i) most popular and (ii) regular menu items excluding value bundles. The median price of the most popular items was significantly higher than the regular menu items for discretionary cereal-based mixed meals $(p=0.011)$, meat or alternative-based mixed meals $(p<0.001)$, savoury sauces, condiments, and spreads $(p=0.025)$ and discretionary vegetable-based mixed meals $(p=0.021)$. However, the median price of the most popular menu items for iced confectionary and dairy-based desserts, was significantly less than the regular menu items $(p=0.036)$.

Figure 2 compares the median price between categories with discretionary and FFG counterparts. The median price for discretionary cereal-based mixed meals $(\$ 14.00)$ was higher than its FFG counterpart $(\$ 12.00, p<0.001)$. The median price of discretionary vegetable-based mixed meals $(\$ 10.00)$ was higher than their FFG counterparts $(\$ 8.90$, $p=0.013$ ). However, the median price of discretionary meat or alternative-based mixed meals $(\$ 15.50)$ was lower than its FFG counterpart $(\$ 17.80, p<0.001)$. 
Table 5. Median price of most popular and regular menu items for each food or beverage category. Value bundles were excluded $(\mathrm{N}=12,734)$.

\begin{tabular}{|c|c|c|c|c|c|c|c|c|}
\hline \multirow{2}{*}{$\begin{array}{c}\text { Food or } \\
\text { Beverage Group }\end{array}$} & \multirow[b]{2}{*}{ Food or Beverage Category } & \multicolumn{3}{|c|}{ Most Popular } & \multicolumn{3}{|c|}{ Regular } & \multirow[t]{2}{*}{$p$-Value } \\
\hline & & $\begin{array}{l}\text { Median } \\
\text { Price (\$) }\end{array}$ & Q1 & Q3 & $\begin{array}{l}\text { Median } \\
\text { Price (\$) }\end{array}$ & Q1 & Q3 & \\
\hline \multirow{8}{*}{$\begin{array}{c}\text { Food } \\
\text { (Discretionary) }\end{array}$} & Cereal-Based Mixed Meal & 14.5 & 12.00 & 17.00 & 14.00 & 10.50 & 17.00 & 0.011 * \\
\hline & Meat Or Alternative-Based Mixed Meal & 17.90 & 14.00 & 22.95 & 15.00 & 10.00 & 19.95 & $0.00 *$ \\
\hline & Savoury Sauces, Condiments And Spreads & 11.50 & 6.99 & 16.00 & 2.00 & 1.30 & 3.00 & $0.025 *$ \\
\hline & Fried Potato (Or Similar) & 7.95 & 6.25 & 8.60 & 6.80 & 5.00 & 8.50 & 0.195 \\
\hline & Baked Goods/Desserts (Homemade Or Similar) & 8.75 & 4.50 & 11.00 & 7.00 & 5.00 & 9.98 & 0.709 \\
\hline & Vegetable-Based Mixed Meal & 15.00 & 10.90 & 16.95 & 9.90 & 7.70 & 15.00 & $0.021 *$ \\
\hline & Iced Confectionary And Dairy-Based Desserts & 5.00 & 2.50 & 5.50 & 6.75 & 5.50 & 10.00 & $0.036 *$ \\
\hline & Other Food $^{a}$ & 8.00 & 7.00 & 9.95 & 5.93 & 3.95 & 10.00 & 0.305 \\
\hline \multirow{4}{*}{ Food (FFG) } & Cereal-Based Mixed Meal & 12.48 & 9.95 & 15.90 & 12.00 & 7.90 & 16.00 & 0.428 \\
\hline & Vegetable-Based Mixed Meal & 12.00 & 8.50 & 13.00 & 8.90 & 8.00 & 12.50 & 0.066 \\
\hline & Meat Or Alternative-Based Mixed Meal & 18.00 & 15.95 & 21.40 & 17.80 & 13.90 & 19.90 & 0.331 \\
\hline & Other Food $^{\mathrm{c}}$ & 6.00 & 3.00 & 8.90 & 8.80 & 8.80 & 8.80 & 0.452 \\
\hline \multirow{3}{*}{$\begin{array}{c}\text { Beverage } \\
\text { (Discretionary) }\end{array}$} & Sugar Sweetened Beverages & - & - & - & 4.40 & 3.50 & 5.50 & - \\
\hline & Other Beverage ${ }^{b}$ & - & - & - & 4.75 & 4.00 & 5.50 & - \\
\hline & Discretionary Milk Based Beverages & 8.45 & 7.90 & 9.00 & 7.50 & 5.00 & 8.50 & 0.384 \\
\hline \multirow{3}{*}{ Beverage (FFG) } & Water & - & - & - & 3.90 & 3.00 & 4.90 & - \\
\hline & Other Beverage $^{d}$ & - & - & - & 4.50 & 4.00 & 6.00 & - \\
\hline & Juice & - & - & - & 4.90 & 4.00 & 5.50 & - \\
\hline
\end{tabular}

${ }^{a}$ Confectionery, Discretionary Snack Food (Savoury)—Packaged, Discretionary Snack Food (Sweet)—Packaged, Other Snack Food (Other), Processed Meats. ${ }^{\mathrm{b}}$ Alcohol, Energy Drinks, Non-Sugar Sweetened Beverages, Rehydration Beverages (Electrolytes), Water Based Flavoured Beverage-Sugar Not Determined. ' Breads And Cereals, Dairy And Alternatives, Fats/Oils, Fruit, Legumes, Meat And Alternatives, Soup, Vegetables, Vegetables (Other). ${ }^{\mathrm{d}}$ Body Building And Performance Beverages, Coffee, Milk/Milk Alternatives, Milk/Milk Alternative Based Beverages, Tea. * $p<0.05$. Q = Quartile.

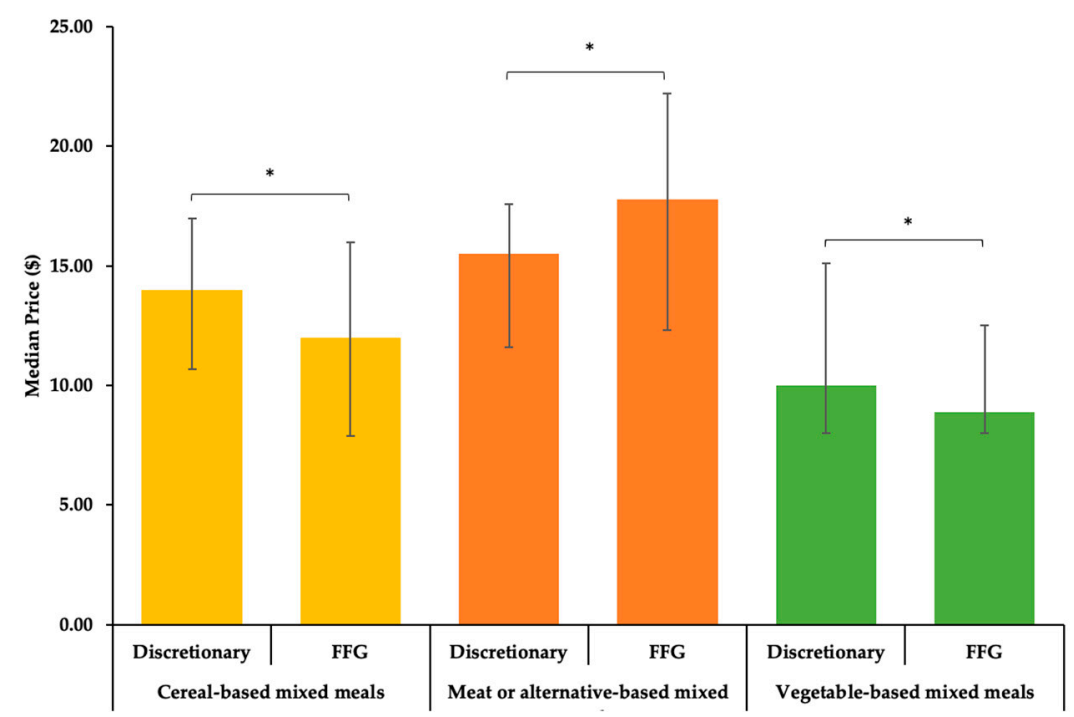

Figure 2. Median price of discretionary and FFG mixed meal categories excluding value bundles. Error bars display interquartile interval, ${ }^{*} p<0.02$.

\subsubsection{Nutritional Information and Dietary Labelling}

Nutritional information was available for 38 menu items and only energy $(\mathrm{kJ})$ values were provided. Dietary labelling was found for 68 menu items, which comprised mostly of 
vegetarian and vegan labels. As both sample sizes were too small ( $<1 \%$ of all menu items), no data analysis was performed.

\section{Discussion}

To our knowledge, this study is the first to evaluate the nutritional quality of complete menus offered by popular independent takeaways on an Australian market-leading OFD platform and examine the association between their nutritional quality and marketing attributes. Discretionary food and beverages made up the majority of menus and were more likely to be most popular, accompanied by an image and offered as a value bundle than FFG menu items. Nutritional and dietary labelling was also largely absent from our sample. Discretionary mixed meals (cereal-based and vegetable-based) were more expensive than their FFG counterparts. Our findings suggest the menus from independent takeaways are dominated by menu items of poor nutritional quality and these menu items appear to be associated with greater use of marketing attributes.

Most menu items offered by popular independent takeaways were discretionary. Similar to our finding, Jaworowska et al. examined 489 commonly consumed meals from small, independent takeaway establishments and found they contributed a large proportion of daily energy and salt intake [17,32,33]. Recently, Goffe et al. also reported 79\% of 149 takeaway food outlets available on the market-leading OFD platform in England, obtained a health rating score of 2 or less out of a maximum of 5 using a novel outlet-level health metric [34]. Our study also identified the majority of most popular menu items to be discretionary. This affirms Partridge et al.'s finding that $84.3 \%$ of most popular menu items were discretionary on the same OFD platform [10]. It is possible that the COVID-19 pandemic may have increased the ordering of unhealthy choices on OFD platforms. A recent observational study in 38 countries reported COVID-19 stay at home policies and COVID-19 induced psychological distress were associated with less preparing and selecting of healthier foods in adults [35]. This is highlighted as UBER reported that compared to the previous year, delivery bookings grew $113 \%$ in the second quarter of 2020 and revenue grew 103\% in August 2020 [36]. More than half of the most popular menu items were discretionary cereal-based mixed meal dishes such as pizzas and burgers. This finding aligns with a recent cross-sectional study across three international cities, including Melbourne, Australia, which studied outlets on OFD platforms located in different socio-demographic areas. They found that in all three cities, burgers and pizza were the most common predefined keywords used to advertise meals [37]. Thus, the discretionary cereal-based mixed meal dishes may be the most popular menu item of independent takeaways as they are amongst the most visible meals on OFD platforms. However, further research is required to confirm that popularity cues influence OFD users to purchase unhealthy choices. A recurring limitation of prior research was analysis of only the most commonly purchased or consumed menu items available from the food outlets investigated $[10,17,33]$. By demonstrating that the poor nutritional quality seen in most popular menu items from popular independent takeaways extends to their complete menus, our findings support that in addition to franchise stores, independent outlets should also be included in current public health nutrition discussions.

Discretionary menu items were more likely to be offered as value bundles and accompanied by an image than FFG menu items. A 2017 study in the US reported consumers were more likely to purchase meal deals when presented with the option than when no option was available [38]. This is a public health concern as value bundles add excessive amounts of deleterious nutrients to already nutritionally poor foods [39]. More recently a study focusing on young people living in Australia also reported increased purchasing intention for menu items that suggested value for money such as meal deals [20]. This same study also reported images to be strong persuaders of consumer choice [20]. Leading OFD platforms themselves have also reported the use of appealing food images to boost sales [40,41]. The value of images is reaffirmed by our finding that images appeared significantly more with the most popular menu items than with regular items. Contrary to our findings, a 2020 experimental study in the US found no effect of pictures on influencing purchase intention or spending 
on a fictious screen, simulating an OFD platform [42]. However, this study was limited to a single menu item, a chicken sandwich, which is not representative of the unhealthier choices found on OFD platforms. The style of image used in this study was also very different to that utilised by UberEats which has specific guidelines for use of images by food outlet partners $[41,43]$. The use of imagery to market poor nutritional quality food has also been noted on other digital platforms, with a recent study reporting $67 \%$ of food images seen by adolescents on social media were of discretionary items [44]. Further research on how images influence the purchasing decisions of a variety of unhealthy choices within OFD platform environments is warranted. Menu labelling has also been reported effective in guiding consumers towards lower caloric options when consuming food prepared out of home $[25,26]$ yet we identified only $0.2 \%$ of menu items offered nutritional information. Despite not analysing consumption data, the absence of nutritional labelling, and the greater proportion of discretionary menu items accompanied by marketing attributes, suggests OFD platforms may be unconducive to positive dietary choices.

Unlike other marketing attributes, the effect of price on consumer choice behaviour has been explored within the specific context of OFD platforms. Schulz et al. reported consumers' exploratory behaviour when selecting a food outlet on a major OFD platform was affected by the outlet's average price compared to others within the same cuisine [45]. The relationship between price and nutritional quality however on OFD platforms has not been explored. A 2011 study conducted in New Zealand evaluating the availability of healthy choices from 24 fast food stores reported that healthier menu items were cheaper than regular options [14]. Our study reported similar results where menu items from two of the three FFG mixed-meal categories were less expensive than their comparable discretionary category. This contrasts with the common perception that healthy choices are more expensive than unhealthy choices, which act as a barrier for young people to select healthier options $[20,46]$. Whilst a statistical significance was noted between the lower prices of healthier options than their discretionary counterparts, it is unknown if a price difference of \$1-\$2 would impact purchasing intention. As taste has been identified as a factor that influences food choices when eating out [20], palatability may be more influential than price. The discretionary meat or alternative-based mixed meal category, which was the second largest discretionary category among the menu items, was cheaper than the FFG counterpart. It is plausible that the FFG meat or alternative-based mixed meals were more expensive as premium, leaner cuts of meat tend to be more expensive than fatty cuts. Ultimately, further research is required to investigate price differences between comparable menu items of opposing nutritional quality on OFD platforms and if this influences consumer choice both independently and in consideration of other platformrelated marketing attributes.

A key strength of this study is the investigation of the largest sample size of complete menus from independent takeways. To our knowledge, only Partridge et al. and Jaworowska et al. have evaluated the nutritional quality of menu items from independent takeaways although were limited to popular menu items only [17,32]. We also employed a comprehensive classification system of 38 food and beverage categories before assigning menu items as discretionary or FFG. This system better defined the offerings from independent takeaways to enhance the understanding of their contribution to the current food environment. Previous research examining the relationship of nutritional quality and food marketing within the digital food environment has focused on online grocery shopping [21]. To our knowledge this is the first study to link the nutritional quality and food marketing attributes for food prepared outside the home within the unique digital environment of OFD platforms. While Partridge et al. [10] demonstrated how OFD platforms increase accessibility to discretionary menu items, this study is one of the first to demonstrate how OFD platforms may also be encouraging the choice of discretionary items over healthier options through marketing tactics.

However, our findings cannot be generalised to all independent takeaways as we only assessed the most popular independent outlets identified by the preceding study [10]. We 
also examined the market-leading OFD platform, however there are others with widespread usage in Australia e.g., Menulog and Deliveroo. Thus, we may have excluded popular outlets exclusive to other OFD platforms and their marketing attributes. As we used web scraping for data extraction, we were limited to the marketing attributes available through the web browser interface and not the mobile application interface. We also could not examine promotions and purchase incentives which are only visible on users' personal accounts. Our findings were interpreted with the assumption that Most Popular referred to items with the greatest sales, however the algorithm used to determine this characteristic is not made publicly available. We also did not examine usage data, thus the associations between nutritional quality and marketing attributes should be interpreted with caution as the findings cannot infer causality.

\section{Conclusions}

The use of OFD platforms as a method to purchase food prepared outside of home is rising and these platforms hold the potential to influence the nutritional quality of the choices users make. The complete menus of the independent takeaways sampled were reported to consist of predominantly unhealthy choices. This demonstrates the need for this food outlet type to be considered in future public health nutrition policy discussions. As we only examined independent takeaways, future research could examine other types of independent outlets, e.g., independent restaurants. Our nutritional analysis was also limited to food and beverage categorisation because we had no access to the complete recipe data of all menu items. To obtain a more detailed nutrient analysis of independent outlets offerings, more detailed food composition data would be needed. The disparity in the use of marketing attributes across discretionary and FFG menu items suggest OFD platforms may be promoting unhealthier options. However, we did not examine consumption nor even sales; thus, the impact remains speculative. We strongly advocate for further research examining how marketing cues in OFD platforms affect nutrition intakes to determine the need to expand menu labelling policies.

Supplementary Materials: The following are available online at https:/ / www.mdpi.com/2072-664 3/13/3/905/s1, Table S1: Food Categories and their definitions with inclusions and exclusions, Table S2: Beverage Categories and their definitions with inclusions and exclusions, Table S3: The proportion of food and beverage categories in the most popular menu items $(n=625)$ from independent takeaways.

Author Contributions: Conceptualization, A.K., C.W., S.S.J., M.A.-F., R.R. (Rajshri Roy), P.P., J.R., A.A.G., and S.R.P.; methodology, A.K., C.W., S.S.J., M.A.-F., V.C., R.R. (Rajshri Roy), R.R. (Rebecca Raeside), P.P., J.R., A.A.G., and S.R.P.; formal analysis, A.K., C.W., S.S.J., M.A.-F., and S.R.P.; writingoriginal draft preparation, A.K. and C.W.; writing-review and editing, A.K., C.W., S.S.J., M.A.-F., V.C., R.R. (Rajshri Roy), R.R. (Rebecca Raeside), P.P., J.R., A.A.G., and S.R.P. All authors have read and agreed to the published version of the manuscript.

Funding: This research was funded by a University of Sydney Cardiovascular Initiative Catalyst Awards Seed Funding Grant for Bioengineering and Digital Science and Charles Perkins Centre Early to Mid-Career Researcher Seed Funding Grant; National Health and Medical Research Council (NHMRC) of Australia and National Heart Foundation (NHF) Early Career Fellowship awarded to S.R.P. (APP1157438); and NHMRC Career Development Fellowship awarded to J.R. (APP1143538); NHMRC Emerging Leader 1 Investigator Grant awarded to A.A.G. (APP1173784).

Institutional Review Board Statement: Not applicable.

Informed Consent Statement: Not applicable.

Data Availability Statement: Publicly available datasets were analyzed in this study. This data can be found here: ubereats.com (accessed on September 10th 2020).

Acknowledgments: The authors thank Anna Singleton, Mariam Mandoh, Allyson R. Todd, Tian Wang, and Nicole K. Halim with data extraction.

Conflicts of Interest: The authors declare no conflict of interest. 


\section{References}

1. Deloitte. Future of Food How Technology and Global Trends are Transforming the Food Industry. Available online: https://www2 .deloitte.com/content/dam/Deloitte/au/Documents/Economics/deloitte-au-economics-future-food-uber-eats-100719.pdf (accessed on 2 September 2020).

2. Lachat, C.; Nago, E.; Verstraeten, R.; Roberfroid, D.; Van Camp, J.; Kolsteren, P. Eating out of home and its association with dietary intake: A systematic review of the evidence. Obes. Rev. 2012, 13, 329-346. [CrossRef]

3. Nielsen. What's in Our Food and on Our Mind Ingredient and Dining-out Trends around the World. Available online: https:// www.nielsen.com/wp-content/uploads/sites/3/2019/04/global-ingredient-and-out-of-home-dining-trends-aug-2016.pdf (accessed on 25 January 2021).

4. Hogan, L. Food Demand in Australia: Trends and Issues 2018; Australian Bureau of Agricultural and Resource Economics and Sciences: Canberra, Australia, 2018.

5. Jaworowska, A.; Blackham, T.; Davies, I.G.; Stevenson, L. Nutritional challenges and health implications of takeaway and fast food. Nutr. Rev. 2013, 71, 310-318. [CrossRef] [PubMed]

6. Smith, K.J.; McNaughton, S.A.; Gall, S.L.; Blizzard, L.; Dwyer, T.; Venn, A.J. Takeaway food consumption and its associations with diet quality and abdominal obesity: A cross-sectional study of young adults. Int. J. Behav. Nutr. Phys. Act. 2009, 6, 29. [CrossRef] [PubMed]

7. Wellard-Cole, L.; Jung, J.; Kay, J.; Rangan, A.; Chapman, K.; Watson, W.L.; Hughes, C.; Mhurchu, C.N.; Bauman, A.; Gemming, L. Examining the Frequency and Contribution of Foods Eaten Away From Home in the Diets of 18-to 30-Year-Old Australians Using Smartphone Dietary Assessment (MYMeals): Protocol for a Cross-Sectional Study. JMIR Res. Protoc. 2018, 7, e24. [CrossRef]

8. Nutrition and Food Systems; The High Level Panel of Experts on Food Security and Nutrition: Rome, Italy, 2017.

9. WHO. Q\&a on Coronaviruses (covid-19): What Is Coronavirus? Available online: https://www.who.int/emergencies/diseases/ novel-coronavirus-2019/question-and-answers-hub/q-a-detail/q-a-coronaviruses (accessed on 25 January 2021).

10. Partridge, S.R.; Gibson, A.A.; Roy, R.; Malloy, J.A.; Raeside, R.; Jia, S.S.; Singleton, A.C.; Mandoh, M.; Todd, A.R.; Wang, T. Junk Food on Demand: A Cross-Sectional Analysis of the Nutritional Quality of Popular Online Food Delivery Outlets in Australia and New Zealand. Nutrients 2020, 12, 3107. [CrossRef] [PubMed]

11. Morgan, R. Meal Delivery Services Double Usage in only 18 Months. Available online: http://www.roymorgan.com/findings/82 70-food-delivery-services-september-2019-202002030451\#: \{\}:text=UberEATS\%20remains\%20the\%20market \%20leader,their\% 20services\%20since \%20mid\%2D2018 (accessed on 29 October 2020).

12. Wellard-Cole, L.; Davies, A.; Allman-Farinelli, M. Contribution of foods prepared away from home to intakes of energy and nutrients of public health concern in adults: A systematic review. Crit. Rev. Food Sci. Nutr. 2021, 10, 1-12. [CrossRef] [PubMed]

13. National Health and Medical Research Council (NHMRC). Australian Dietary Guidelines; National Health and Medical Research Council: Canberra, Australia, 2013.

14. Chand, A.; Eyles, H.; Ni Mhurchu, C. Availability and accessibility of healthier options and nutrition information at New Zealand fast food restaurants. Appetite 2012, 58, 227-233. [CrossRef]

15. Muc, M.; Jones, A.; Roberts, C.; Sheen, F.; Haynes, A.; Robinson, E. A bit or a lot on the side? Observational study of the energy content of starters, sides and desserts in major UK restaurant chains. BMJ Open 2019, 9. [CrossRef] [PubMed]

16. Needham, C.; Orellana, L.; Allender, S.; Sacks, G.; Blake, M.R.; Strugnell, C. Food retail environments in Greater Melbourne 2008-2016: Longitudinal analysis of intra-city variation in density and healthiness of food outlets. Int. J. Environ. Res. Public Health 2020, 17, 1321. [CrossRef]

17. Jaworowska, A.; Toni, M.B.; Long, R.; Taylor, C.; Ashton, M.; Stevenson, L.; Glynn Davies, I. Nutritional composition of takeaway food in the UK. Food Sci. Nutr. 2014, 44, 414-430. [CrossRef]

18. Reddy, C.S.; Aradhya, G.B. Driving Forces for the Success of Food Ordering and Delivery Apps: A Descriptive Study. Int. J. Eng. Manag. Res. 2020, 10, 131-134. [CrossRef]

19. Bates, S.; Reeve, B.; Trevena, H. A narrative review of online food delivery in Australia: Challenges and opportunities for public health nutrition policy. Public Health Nutr. 2020, 10, 1-11. [CrossRef]

20. Allman-Farinelli, M.; Rahman, H.; Nour, M.; Wellard-Cole, L.; Watson, W.L. The Role of Supportive Food Environments to Enable Healthier Choices When Eating Meals Prepared Outside the Home: Findings from Focus Groups of 18 to 30-Year-Olds. Nutrients 2019, 11, 2217. [CrossRef]

21. Breugelmans, E.; Campo, K.; Gijsbrechts, E. Shelf sequence and proximity effects on online grocery choices. Mark. Lett. 2007, 18, 117-133. [CrossRef]

22. Campbell, S.; James, E.L.; Stacey, F.G.; Bowman, J.; Chapman, K.; Kelly, B. A mixed-method examination of food marketing directed towards children in Australian supermarkets. Health Promot. Int. 2012, 29, 267-277. [CrossRef]

23. Dayan, E.; Bar-Hillel, M. Nudge to nobesity II: Menu positions influence food orders. Judgm. Decis. Mak. 2011, 6, $333-342$.

24. Hwang, Y.; Su, N.; Mattila, A. The interplay between social crowding and power on solo diners' attitudes toward menus with popularity and scarcity cues. Int. J. Contemp. Hosp. Manag. 2020, 32, 1227-1246. [CrossRef]

25. Hillier-Brown, F.C.; Summerbell, C.D.; Moore, H.J.; Routen, A.; Lake, A.A.; Adams, J.; White, M.; Araujo-Soares, V.; Abraham, C.; Adamson, A.J.; et al. The impact of interventions to promote healthier ready-to-eat meals (to eat in, to take away or to be delivered) sold by specific food outlets open to the general public: A systematic review. Obes. Rev. 2016, 18, 227-246. [CrossRef] 
26. Littlewood, J.A.; Lourenço, S.; Iversen, C.L.; Hansen, G.L. Menu labelling is effective in reducing energy ordered and consumed: A systematic review and meta-analysis of recent studies. Public Health Nutr. 2016, 19, 2106-2121. [CrossRef] [PubMed]

27. Hallez, L.; Qutteina, Y.; Raedschelders, M.; Boen, F.; Smits, T. That's my cue to eat: A systematic review of the persuasiveness of front-of-pack cues on food packages for children vs. adults. Nutrients 2020, 12, 1062. [CrossRef]

28. Roy, R.; Alassadi, D. Does labelling of healthy foods on menus using symbols promote better choices at the point-of-purchase? Public Health Nutr. 2020, 1-9. [CrossRef] [PubMed]

29. Thornton, L.E.; Kavanagh, A.M. Association between fast food purchasing and the local food environment. Nutr. Diabetes 2012, 2. [CrossRef] [PubMed]

30. Moayyed, H.; Kelly, B.; Feng, X.; Flood, V. Evaluation of a 'healthiness' rating system for food outlet types in Australian residential communities. Nutr. Diet. 2017, 74, 29-35. [CrossRef]

31. A.B.S. Australian Health Survey: Users' Guide, 2011-13: Discretionary Foods. Available online: https://www.abs.gov.au/ausstats/ abs@.nsf/Lookup/4363.0.55.001Chapter65062011-13 (accessed on 28 November 2020).

32. Jaworowska, A.; Blackham, T.; Stevenson, L. Nutritional composition of takeaway meals served by independent small outlets. Proc. Nutr. Soc. 2011, 70, 1. [CrossRef]

33. Jaworowska, A.; Blackham, T.; Stevenson, L.; Davies, I.G. Determination of salt content in hot takeaway meals in the United Kingdom. Appetite 2012, 59, 517-522. [CrossRef] [PubMed]

34. Goffe, L.; Uwamahoro, N.S.; Dixon, C.J.; Blain, A.P.; Danielsen, J.; Kirk, D.; Adamson, A.J. Supporting a Healthier Takeaway Meal Choice: Creating a Universal Health Rating for Online Takeaway Fast-Food Outlets. Int. J. Environ. Res. Public Health 2020, 17, 9260. [CrossRef] [PubMed]

35. De Backer, C.J.; Teunissen, L.; Cuykx, I.; Decorte, P.; Pabian, S.; Gerritsen, S.; Matthys, C.; Al Sabbah, H.; Van Royen, K. An evaluation of the COVID-19 pandemic and social distancing policies in relation to planning, selecting, and preparing healthy meals: An observational study in 38 countries worldwide. Front. Nutr. 2021, 7, 621726. [CrossRef]

36. Uber. Uber Announces Results for Second Quarter 2020. Available online: https://investor.uber.com/news-events/news/pressrelease-details / 2020/Uber-Announces-Results-for-Second-Quarter-2020/default.aspx (accessed on 9 February 2021).

37. Poelman, M.P.; Thornton, L.; Zenk, S.N. A cross-sectional comparison of meal delivery options in three international cities. Eur. J. Clin. Nutr. 2020, 1-9. [CrossRef] [PubMed]

38. Harris, J.; Thomas, V.L. The Influence of Bundling and Caloric Knowledge on Calories Ordered and Purchase Intent. J. Consum. Aff. 2017, 51, 113-132. [CrossRef]

39. Cameron-Smith, D.; Bilsborough, S.A.; Crowe, T.C. Upsizing Australia's waistline: The dangers of "meal deals". Med. J. Aust. 2002, 177, 686. [CrossRef] [PubMed]

40. Parker, S. Deliveroo foodscene-How Does Photography Impact Sales? Available online: https://foodscene.deliveroo.co.uk/ restaurant-profiles/menu-photography-how-does-it-impact-sales.html (accessed on 14 November 2020).

41. Grubhub. Growing your Business with Food Photography-Food Photography Made Easy. Available online: https://learn.grubhub. com/wp-content/uploads/2017/11/B2B_20170815_RestaurantPhotoGuidelines_FINAL-1.pdf (accessed on 14 November 2020).

42. Gunden, N.; Morosan, C.; DeFranco, A. Are online food delivery systems persuasive? The impact of pictures and calorie information on consumer behavior. J. Hosp. Tour. Insights 2020. [CrossRef]

43. Gala, P.; Rippe, C.B.; Dubinsky, A.J.; Favia, M.J. Effects of menu calorie information and product image on millenials' purchase intention. J. Mark. Manag. 2018, 28, 127-144.

44. Qutteina, Y.; Hallez, L.; Mennes, N.; De Backer, C.; Smits, T. What Do Adolescents See on Social Media? A Diary Study of Food Marketing Images on Social Media. Front. Psychol. 2019, 10. [CrossRef] [PubMed]

45. Schulz, E.; Bhui, R.; Love, B.C.; Brier, B.; Todd, M.T.; Gershman, S.J. Structured, uncertainty-driven exploration in real-world consumer choice. Proc. Natl. Acad. Sci. USA 2019, 116, 13903-13908. [CrossRef]

46. Haws, K.L.; Reczek, R.W.; Sample, K.L. Healthy diets make empty wallets: The healthy = expensive intuition. J. Consum. Res. 2017, 43, 992-1007. [CrossRef] 